\title{
Fatty acid metabolism during maturation affects glucose uptake and is essential to oocyte competence
}

\author{
M Paczkowski, W B Schoolcraft ${ }^{1}$ and R L Krisher \\ National Foundation for Fertility Research, 10290 Ridgegate Circle, Lone Tree, Colorado 80124, USA and ${ }^{1}$ Colorado \\ Center for Reproductive Medicine, 10290 Ridgegate Circle, Lone Tree, Colorado 80124, USA
}

Correspondence should be addressed to R L Krisher; Email: rkrisher@fertilityresearch.org

\begin{abstract}
Fatty acid $\beta$-oxidation (FAO) is essential for oocyte maturation in mice. The objective of this study was to determine the effect of etomoxir (a FAO inhibitor; $100 \mu \mathrm{M})$, carnitine $(1 \mathrm{mM})$, and palmitic acid (1 or $100 \mu \mathrm{M})$ during maturation on metabolism and gene expression of the oocyte and cumulus cells, and subsequent embryo development in the mouse. Carnitine significantly increased embryo development, while there was a decrease in development following maturation with $100 \mu \mathrm{M}$ palmitic acid or etomoxir $(P<0.05)$ treatment. Glucose consumption per cumulus-oocyte complex (COC) was decreased after treatment with carnitine and increased following etomoxir treatment $(P<0.05)$. Intracellular oocyte lipid content was decreased after carnitine or etomoxir exposure $(P<0.05)$. Abundance of Slc2a1 (Glut1) was increased after etomoxir treatment in the oocyte and cumulus cells $(P<0.05)$, suggesting stimulation of glucose transport and potentially the glycolytic pathway for energy production when FAO is inhibited. Abundance of carnitine palmitoyltransferase $2(C p t 2)$ tended to increase in oocytes $(P=0.1)$ after treatment with $100 \mu \mathrm{M}$ palmitic acid and in cumulus cells after exposure to $1 \mu \mathrm{M}$ palmitic acid $(P=0.07)$. Combined with carnitine, $1 \mu \mathrm{M}$ palmitic acid increased the abundance of $A c s / 3(P<0.05)$ and Cpt 2 tended to increase $(P=0.07)$ in cumulus cells, suggesting FAO was increased during maturation in response to stimulators and fatty acids. In conclusion, fatty acid and glucose metabolism are related to the mouse $\mathrm{COC}$, as inhibition of FAO increases glucose consumption. Stimulation of FAO decreases glucose consumption and lipid stores, positively affecting subsequent embryo development, while an overabundance of fatty acid or reduced FAO negatively affects oocyte quality.

Reproduction (2014) 148 429-439
\end{abstract}

\section{Introduction}

Supplementation of media with energy substrates such as glucose or pyruvate is critical for the successful completion of oocyte nuclear and cytoplasmic maturation as well as development of the resulting embryo (Biggers et al. 1967, Downs \& Mastropolo 1994, Spindler et al. 2000, Herrick et al. 2006a,b). However, recent work has shown that fatty acid $\beta$-oxidation (FAO) is another important energy source during oocyte maturation (Hewitson et al. 1996, Ferguson \& Leese 2006, Sturmey et al. 2006, 2009, Downs et al. 2009, Dunning et al. 2010, Paczkowski et al. 2013). The oxidation of a single fatty acid can produce up to 106 ATP molecules (Berg et al. 2002) and thus could be an efficient source of energy production for the maturing oocyte and pre-implantation embryo.

During FAO, the rate-limiting step is the transport of fatty acids bound to carnitine across the mitochondrial membrane, which is catalyzed by carnitine palmitoyltransferase 1 (CPT1). Carnitine is then removed from the fatty acid via CPT2, allowing the fatty acid to undergo $\beta$-oxidation within the mitochondria (McGarry \& Brown
1997). Supplementation of exogenous fatty acids, such as palmitic acid, and carnitine increase the abundance of Cpt1 in pancreatic $\beta$-cell lines, thereby increasing the rate of FAO (Assimacopoulos-Jeannet et al. 1997). Conversely, exposure to the pharmacological CPT1 inhibitor etomoxir prevents the transport of fatty acids across the mitochondrial membrane and reduces FAO (Ferguson \& Leese 2006).

The importance of FAO to oocyte nuclear maturation (attainment of metaphase II and extrusion of the first polar body) is correlated to the relative concentration of intracellular lipids within the oocytes of different species (Paczkowski et al. 2013). Porcine oocytes, which contain relatively high intracellular lipid content, are more sensitive to inhibition of FAO by etomoxir than mouse (few intracellular lipids) or bovine (moderate amount of intracellular lipids) oocytes. Higher concentrations of etomoxir are required to block nuclear maturation in the mouse than in the pig, suggesting that mouse oocytes may not rely as heavily on FAO as other species (Paczkowski et al. 2013). However, several studies demonstrate that $\mathrm{FAO}$ is required to complete nuclear maturation in the mouse (Hewitson et al. 1996, Downs 
et al. 2009, Dunning et al. 2010, Paczkowski et al. 2013, Valsangkar \& Downs 2013). Exposure to high concentrations of etomoxir $(250 \mu \mathrm{M})$ during maturation inhibits the completion of meiosis in mouse oocytes (Paczkowski et al. 2013). After exposure to a lower concentration of etomoxir $(100 \mu \mathrm{M})$, oocytes are able to complete nuclear maturation (Dunning et al. 2010, Paczkowski et al. 2013), albeit with a decrease in development of embryo to the blastocyst stage post fertilization (Dunning et al. 2010).

The objective of these experiments was to evaluate the effect of a FAO stimulator (carnitine) and inhibitor (etomoxir), as well as a fatty acid (palmitic acid), on oocyte and cumulus cell gene expression; metabolic parameters including oocyte lipid content, glucose consumption by the cumulus-oocyte complex (COC), and ATP quantification in oocytes and cumulus cells; and subsequent embryonic development and cell allocation in a complete maturation medium that supports oocyte competence. Based on our previous studies (Paczkowski et al. 2013), the dosage of etomoxir $(100 \mu \mathrm{M})$ was selected to allow completion of oocyte nuclear maturation while potentially compromising cytoplasmic maturation.

\section{Materials and methods}

All chemicals and reagents were purchased from SigmaAldrich unless otherwise stated.

\section{In vitro maturation, fertilization, and culture}

B6D2F1 female mice, $\sim 3$ weeks of age, were administered pregnant mare serum gonadotropin (5 IU, i.p.; EMD Biosciences, Billerica, MA, USA) $48 \mathrm{~h}$ before being killed. The ovaries were harvested and washed in GMOPS PLUS (Vitrolife, Englewood, CO, USA) supplemented with 5\% FCS (HyClone, Thermo Scientific, Rockford, IL, USA). The oocytes surrounded by a complete layer of cumulus cells were recovered by ovarian dissection and matured in vitro for $18 \mathrm{~h}$ at $37{ }^{\circ} \mathrm{C}, 8.3 \% \mathrm{CO}_{2}$ and $6.3 \% \mathrm{O}_{2}$. Owing to the increased altitude of Lone Tree, Colorado, the $\mathrm{CO}_{2}$ level was increased to maintain the $\mathrm{pH}$ of all media at 7.28. A completely defined oocyte maturation media was supplemented with $0.5 \mathrm{mM}$ glucose, $6 \mathrm{mM}$ lactate (MP Biomedicals, Santa Ana, CA, USA), $0.2 \mathrm{mM}$ pyruvate, $10 \mathrm{ng} / \mathrm{ml}$ epidermal growth factor (EGF), $0.5 \mathrm{mg} / \mathrm{ml} \mathrm{G-MM}$ Recombumin (Vitrolife), and $2 \mathrm{mg} / \mathrm{ml}$ fetuin. This medium is our standard mouse maturation medium and successfully supports oocyte nuclear and cytoplasmic maturation. The COCs were matured in one of seven treatment groups: i) control; ii) $1 \mathrm{mM}$ carnitine (CARN); iii) $1 \mu \mathrm{M}$ palmitic acid ( $1 \mu \mathrm{M}$ PALM); iv) $100 \mu \mathrm{M}$ palmitic acid (100 $\mu \mathrm{M}$ PALM); v) $1 \mathrm{mM}$ carnitine plus $1 \mu \mathrm{M}$ palmitic acid (CARN $+1 \mu \mathrm{M}$ PALM); vi) $1 \mathrm{mM}$ carnitine plus $100 \mu \mathrm{M}$ palmitic acid (CARN+ $100 \mu \mathrm{M}$ PALM); and vii) $1 \mathrm{mM}$ carnitine plus $100 \mu \mathrm{M}$ etomoxir $(\mathrm{CARN}+\mathrm{ETO})$. As EGF is present in the basal media, FAO is expected to be an active pathway in the COC; therefore, supplementation of carnitine to the basal medium may further augment FAO. The concentrations of 1 and $100 \mu \mathrm{M}$ palmitic acid used are similar to those reported in bovine follicular fluid during both a normal physiological state and negative energy balance with elevated lipolysis (Leroy et al. 2005, Van Hoeck et al. 2011). All mouse protocols were approved by the National Foundation for Fertility Research (NFFR) Ethics in Research Committee and followed animal care and use guidelines, as described by the Guide for the Care and Use of Laboratory Animals (National Research Council 2011).

The COCs were transferred to human tubal fluid (HTF; Nagy et al. 2003) supplemented with $0.4 \mathrm{~g}$ BSA (MP Biomedicals) post maturation. The spermatozoa were collected from the vas deferens and cauda epididymis of an adult B6D2F1 male ( $>10$ weeks of age) and incubated at $37{ }^{\circ} \mathrm{C}, 8.3 \% \mathrm{CO}_{2}$ and $6.3 \% \mathrm{O}_{2}$ in HTF for $1 \mathrm{~h}$ to allow for capacitation. They were further diluted in HTF and added to the fertilization drops for a final concentration of $1 \times 10^{6} \mathrm{sperm} / \mathrm{ml}$. The gametes were then co-incubated for $6 \mathrm{~h}$.

Presumptive zygotes were cultured in G1 PLUS (Vitrolife) at $37{ }^{\circ} \mathrm{C}, 8.3 \% \mathrm{CO}_{2}$ and $6.3 \% \mathrm{O}_{2}$ for $48 \mathrm{~h}$. Cleavage was assessed $22 \mathrm{~h}$ post insemination (hpi). After $48 \mathrm{~h}$ of culture, embryos were transferred to G2 PLUS (Vitrolife) for an additional $64 \mathrm{~h}$ and blastocyst development was assessed on day 4 (96 hpi). The blastocysts were stained for inner cell mass (ICM), trophectoderm (TE), and total cell number (Thouas et al. 2001) on day 5 (112 hpi). Briefly, blastocysts were incubated in $300 \mu \mathrm{g} / \mathrm{ml}$ propidium iodide and $1.25 \%$ Triton X-100 in PBS for $5 \mathrm{~s}$ and then incubated in $0.25 \mu \mathrm{g} / \mathrm{ml}$ bizbenzimide (Hoescht 33258 ) in $100 \%$ ethanol overnight at $4{ }^{\circ} \mathrm{C}$. The blastocysts were mounted on glass slides in a drop of glycerol under a cover slip. The cell numbers were counted by fluorescent microscopy.

\section{Quantitative PCR}

The COCs were matured in vitro for $18 \mathrm{~h}$ as described earlier. The oocytes were mechanically denuded following in vitro maturation (IVM) using a pulled glass pipette and the cumulus cells were isolated from maturation media via centrifugation at $16000 \mathrm{~g}$ for $5 \mathrm{~min}$. The oocytes that had reached metaphase II, indicated by the extrusion of the first polar body, were frozen at $-80{ }^{\circ} \mathrm{C}$ in groups of ten oocytes per treatment in PicoPure lysis buffer (Applied Biosystems). Four biological replicates of ten oocytes each were collected for each treatment. RNA was extracted using the PicoPure RNA Isolation Kit (Applied Biosystems) with on-column DNase treatment (Qiagen). Total RNA extracted from oocytes and cumulus cells were loaded into the cDNA reaction; therefore, the resulting quantitative PCR ( $\mathrm{PPCR}$ ) data were analyzed by relative quantification as described below. cDNA was synthesized using the High Capacity cDNA RT Kit (Applied Biosystems) following the manufacture's protocol.

Primer design and qPCR were performed as previously described (Paczkowski et al. 2011, 2013). Primers for genes related to FAO (acyl-coenzyme A dehydrogenase long-chain (Acadl), acyl-CoA synthetase long-chain family member 3 (Acsl3), and Cpt2), glucose transport (glucose transporter 1 (Slc2a1 (Glut1))), and oxidative stress (glutaredoxin 2 (Glrx2) and thioredoxin reductase 1 (Txnrd1)) were designed for qPCR using Primer3 (Rozen \& Skaletsky 2000). 
Peptidylprolylisomerase A (Ppia) was used as the reference gene as transcript abundance remained stable (not statistically different) between treatments. Accession number, primer sequence, and product length of target and reference genes are presented in Table 1 . Primer specificity was determined by melt-curve analysis and gel electrophoresis, and resulting PCR products were cloned into $\mathrm{pCR} 2.1$ TOPO vectors and transformed into One Shot TOP10 chemically competent Escherichia coli (Invitrogen Life Technologies). The plasmids were sequenced in the DNA-sequencing facility at Colorado State University (Fort Collins, CO, USA) to confirm the identity of the transcript and quantified using the Quant-iT PicoGreen dsDNA Assay Kit (Invitrogen Life Technologies). QPCR was carried out on threefold diluted sample cDNA run in duplicate. The target genes were analyzed using iQ SYBR Green Supermix (Bio-Rad) and an Applied Biosystems 7300 Real-Time PCR system. A standard curve was generated from serial dilutions of EcoRI-digested plasmids $\left(10^{7}-10^{1}\right.$ molecules) and the efficiency of the primers was calculated.

\section{Metabolic assays}

\section{Glucose colorimetric assay}

At $18 \mathrm{~h}$ post maturation, maturation media from the seven treatment groups was snap frozen and stored at $-80^{\circ} \mathrm{C}$. For each treatment, spent (media that had been exposed to ten COC) and unspent media (media that had not been exposed to COC) were collected from each dish. Glucose concentrations were determined using the Glucose Assay Kit (BioVision, Mountain View, CA, USA) following the manufacturer's instructions. Briefly, $25 \mu \mathrm{l}$ of media were diluted 1:2 and incubated with $2 \mu \mathrm{l}$ glucose probe, $2 \mu \mathrm{l}$ glucose enzyme mix, and $46 \mu \mathrm{l}$ assay buffer for $30 \mathrm{~min}$ at $37^{\circ} \mathrm{C}$, protected from light. After incubation, samples were read immediately on an EPOCH microplate reader (BioTek, Winooski, VT, USA). To determine glucose concentration $(\mathrm{mM})$, the average amount of glucose (nmol) in each well was divided by the volume of sample analyzed. To determine glucose consumption (pmol/COC per h) during oocyte maturation, the concentration obtained from the spent media was subtracted from the average concentration of unspent media and converted to picomole glucose using the volume of the drop used for maturation $(50 \mu \mathrm{l})$, the number of COC per drop (ten COC), and the length of maturation (18 h). It is important to note that glucose consumption values were not corrected for the number of cumulus cells per drop, but are based on the number of COC. A limit of this methodology is that if differences exist in cumulus cell number, resulting either from the initial cumulus investment or treatment effects on cumulus cell survival and/or viability, they are not reflected.

\section{ATP concentration}

COCs were matured in vitro and oocytes and cumulus cells were collected separately as described earlier. Denuded oocytes were pooled into three biological replicates of ten oocytes per treatment and frozen at $-80^{\circ} \mathrm{C}$ in $10 \mu \mathrm{l} \mathrm{PBS}$. ATP concentrations, in pmol ATP/oocyte, were calculated using the ApoSENSOR Assay Kit and standard curve (BioVision), following the manufacturer's instructions.

\section{Lipid content}

Lipid content was analyzed by Nile red staining as previously described (Genicot et al. 2005), with slight modifications. Briefly, after IVM, the oocytes were denuded and fixed for a minimum of $24 \mathrm{~h}$ in $500 \mu \mathrm{l}$ of a $2 \%$ glutaraldehyde and $2 \%$ formaldehyde solution. The oocytes were then stained overnight in $10 \mu \mathrm{g} / \mathrm{ml}$ Nile red. Images were taken at $200 \times$ on a fluorescent microscope and analyzed using the freely available Image) software (version 1.46, National Institutes of Health, Bethesda, MD, USA; Marei et al. 2012). The mean signal intensity for each oocyte and background was determined three times and used to calculate the final signal intensity of each oocyte.

\section{Statistical analyses}

Percent oocyte maturation, embryonic cleavage, and blastocyst development (of total oocytes and of cleaved embryos) were analyzed using the generalized linear mixed model (GLIMMIX) procedure in SAS (SAS Institute, Inc., Cary, NC, USA) with a binomial error distribution and a probit link function (Littell et al. 1996), as each embryo was scored as a 1 or 0 depending on whether or not it achieved the desired stage of development (MIl oocyte, cleaved embryo, or blastocyst; Herrick et al. 2014). In all analyses, treatment was considered to be a fixed factor and replicate was included as a random factor. Cell number, glucose concentration, ATP concentration, and lipid content were normally distributed and were analyzed by a one-way ANOVA using Number Cruncher Statistical System (NCSS, Kaysville, UT, USA). When ANOVA detected

Table 1 Summary of quantitative PCR primers of target and reference genes in the mouse.

\begin{tabular}{|c|c|c|c|c|c|}
\hline Gene symbol & Accession number & Forward primer sequence & Reverse primer sequence & $\begin{array}{c}\text { Product } \\
\text { length (bp) }\end{array}$ & $\begin{array}{c}\text { Sequence } \\
\text { identity }(\%)^{\mathrm{a}}\end{array}$ \\
\hline Acadl & NM_007381 & $5^{\prime}$-cttgcttggcatcaacatc- $3^{\prime}$ & $5^{\prime}$-ttcgcaatatagggcatga-3' & 150 & 100 \\
\hline Acsl3 & NM_001033606 & $5^{\prime}$-tgctgagcttgtgtgtcttt- $3^{\prime}$ & $5^{\prime}$-gatccgatccatgatttcc-3' & 160 & 100 \\
\hline Cpt2 & NM_009949 & $5^{\prime}$-tgctcgctcaggataaacag-3' & $5^{\prime}$-cggattgaatgccatgaa- $3^{\prime}$ & 122 & 100 \\
\hline Glrx2 & NM_001038592 & $5^{\prime}$-gttccatggccaagaagatt-3' & $5^{\prime}$-gcctccaataaatcgtccat-3' & 161 & 99 \\
\hline Slc2a1 & NM_011400 & $5^{\prime}$-ggcctgactactggctttgt-3' & $5^{\prime}$-agaggccacaagtctgcatt- $3^{\prime}$ & 164 & 100 \\
\hline Txnrd1 & NM_001042513 & $5^{\prime}$-acaatgaatggctccaaaga- $3^{\prime}$ & $5^{\prime}$-aaatttggctgcctccttag-3' & 105 & 100 \\
\hline Ppia & NM_008907 & $5^{\prime}$-ggcaaatgctggaccaaa-3' & $5^{\prime}$-tcagtcttggcagtgcagata-3' & 60 & 100 \\
\hline
\end{tabular}

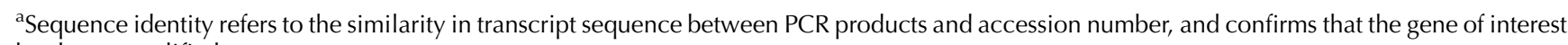
has been amplified. 
significant differences $(P<0.05)$, treatment differences were determined using a Fisher's least significant difference (LSD) multiple comparison test. For relative quantification, data were analyzed using the relative expression software tool, REST 2005 version 1.9.12 (Pfaffl et al. 2002). The expression ratios were generated from equation (1) using PCR efficiencies $(E)$ of the target and reference genes and the $\Delta C T$ values of the control and sample (treatment) oocytes or cumulus cells. The threshold cycle $(C T)$ values represent the PCR cycle when the SYBR Green fluorescence rises above the background fluorescence or threshold. The levels of significance were calculated by pairwise fixed reallocation randomization tests with 50000 iterations and significance was determined with a $P$ value $<0.05$.

Ratio $=\frac{\left(E_{\text {target }}\right)^{\Delta C \mathrm{~T} \text { target (control-sample) }}}{\left(E_{\text {ref }}\right)^{\Delta C \mathrm{~T} \text { ref (control-sample) }}}$.

\section{Results}

\section{Oocyte maturation and embryo development}

We hypothesized that embryonic development would be decreased after FAO inhibition during IVM, whereas a FAO stimulator, carnitine, would increase embryonic development. Furthermore, exogenous palmitic acid would increase embryonic development when supplemented alone or in conjunction with carnitine. There were no significant differences in the percentage of oocytes completing nuclear maturation in oocytes matured in CARN or CARN + ETO compared with control oocytes $(P>0.05$; Table 2$)$. Nuclear maturation of oocytes matured in $100 \mu \mathrm{M}$ PALM and CARN + $100 \mu \mathrm{M}$ PALM were significantly decreased compared with control oocytes $(P<0.05$; Table 2$)$. Cleavage of oocytes matured in CARN post fertilization was not different compared with control oocytes $(P>0.05$; Fig. 1); however, there was a significant increase in day 4 blastocysts of both cleaved embryos and of total presumptive zygotes $(P<0.05)$ after oocyte maturation in CARN. Cleavage and day 4 blastocyst of total presumptive zygotes were significantly reduced in the $100 \mu \mathrm{M}$ PALM treatment compared with control oocytes $(P<0.05)$; however, the addition of carnitine

Table 2 Nuclear maturation of mouse oocytes after treatment with $1 \mathrm{mM}$ carnitine (CARN), $100 \mu \mathrm{M}$ palmitic acid (100 $\mu \mathrm{M}$ PALM), carnitine plus $100 \mu \mathrm{M}$ palmitic acid (CARN+100 $\mu \mathrm{M}$ PALM), or carnitine plus $100 \mu \mathrm{M}$ etomoxir (CARN+ETO).

\begin{tabular}{lcc}
\hline Treatment & $\boldsymbol{n}$ & Percent $(\%)$ \\
\hline Control & 102 & $98.04 \pm 1.38^{*,+}$ \\
CARN & 102 & $99.02 \pm 9.80^{*}$ \\
$100 \mu \mathrm{M}$ PALM & 104 & $91.35 \pm 2.77^{\ddagger}$ \\
CARN + 100 $\mu \mathrm{M}$ PALM & 100 & $90.00 \pm 3.02^{\ddagger}$ \\
CARN + ETO & 106 & $94.34 \pm 2.26^{\dagger, \neq}$
\end{tabular}

${ }^{*}, t,{ }^{*}$ Columns across treatments with different symbols are significantly different, $P<0.05$.

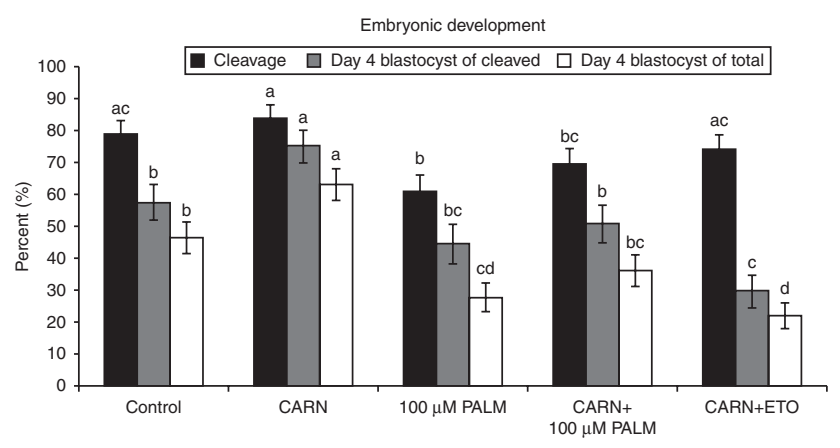

Figure 1 Embryonic development after oocyte maturation with $1 \mathrm{mM}$ carnitine (CARN), $100 \mu \mathrm{M}$ palmitic acid (100 $\mu \mathrm{M}$ PALM), carnitine plus $100 \mu \mathrm{M}$ palmitic acid (CARN + $100 \mu \mathrm{M}$ PALM), or carnitine plus $100 \mu \mathrm{M}$ etomoxir (CARN + ETO). ${ }^{\mathrm{a}, \mathrm{b}, \mathrm{c}, \mathrm{d}}$ Columns across treatments with different letters are significantly different, $P<0.05$.

$(\mathrm{CARN}+100 \mu \mathrm{M}$ PALM) was able to rescue embryo development on day 4 such that it was not different than control $(P>0.05$; Fig. 1). Supplementation of CARN + ETO significantly decreased day 4 blastocyst development (per zygote and per cleaved embryo) compared with controls $(P<0.05$; Fig. 1$)$.

Because supplementation of $100 \mu \mathrm{M}$ PALM was inhibitory to maturation and embryonic development, we subsequently analyzed these parameters after supplementation with a lower concentration of palmitic acid $(1 \mu \mathrm{M}$ PALM). Reducing the concentration of palmitic acid alone $(1 \mu \mathrm{M})$ or in conjunction with carnitine did not significantly alter nuclear maturation, embryo cleavage, or the proportion of day 4 blastocysts of total presumptive zygotes compared with control oocytes respectively $(P>0.05)$. However, the proportion of day 4 blastocysts of cleaved embryos was reduced $(78.90 \pm 3.93$ vs $88.99 \pm 3.01 \% ; P<0.05)$ in the lower concentration of palmitic acid $(1 \mu \mathrm{M})$ compared with control oocytes respectively.

Supplementation of carnitine (CARN) or palmitic acid (1 $\mu \mathrm{M}$ PALM), or the combination of the two (CARN+ $1 \mu \mathrm{M}$ PALM), did not affect total cell number or the number of TE cells compared with control embryos ( $P>0.05$; Table 3$)$. However, the number of cells within the ICM was significantly decreased in the embryos derived from oocytes matured in $1 \mu \mathrm{M}$ PALM or CARN + $1 \mu \mathrm{M}$ PALM compared with controls $(P<0.05)$. Addition of etomoxir (CARN +ETO) during maturation significantly decreased the number of total, TE, and ICM cells $(P<0.05$; Table 3$)$. There were no significant differences in the ICM:TE ratio (data not shown) or in the percent of ICM cells of total blastocyst cells between any of the treatments and control ( $P>0.05$; Table 3).

\section{Gene expression}

We hypothesized that transcript abundance of genes involved in FAO would be increased in the oocyte and 
Table 3 Total, trophectoderm (TE), and inner cell mass (ICM) cell numbers following in vitro maturation and fertilization after treatment with $1 \mathrm{mM}$ carnitine (CARN), $1 \mu \mathrm{M}$ palmitic acid $(1 \mu \mathrm{M}$ PALM), carnitine plus $1 \mu \mathrm{M}$ palmitic acid (CARN $+1 \mu \mathrm{M}$ PALM), or carnitine plus $100 \mu \mathrm{M}$ etomoxir $(\mathrm{CARN}+\mathrm{ETO})$.

\begin{tabular}{lccccc}
\hline Treatment & $\boldsymbol{n}$ & Total & TE & ICM & \% ICM of total \\
\hline Control & 67 & $99.18 \pm 4.30^{*}$ & $93.96 \pm 3.85^{*}$ & $16.25 \pm 0.96^{*}$ & $14.74 \pm 0.61^{*}$ \\
CARN & 60 & $93.28 \pm 3.95^{*}$ & $87.38 \pm 3.62^{*}$ & $15.41 \pm 1.22^{*, *}$ & $15.17 \pm 1.08^{*}$ \\
$1 \mu \mathrm{M}$ PALM & 58 & $88.97 \pm 4.58^{*}$ & $84.42 \pm 6.34^{*}$ & $12.31 \pm 0.91^{+}$ & $13.55 \pm 0.93^{*}$ \\
CARN + $1 \mu \mathrm{M}$ PALM & 46 & $93.13 \pm 5.56^{*}$ & $87.20 \pm 7.41^{*}$ & $12.95 \pm 0.73^{+, \neq}$ & $14.35 \pm 1.35^{*}$ \\
CARN +ETO & 38 & $65.97 \pm 4.20^{+}$ & $56.93 \pm 3.59^{+}$ & $10.00 \pm 0.88^{+}$ & $15.25 \pm 1.31^{*}$ \\
\hline
\end{tabular}

${ }^{*, t, \neq}$ Columns across treatments with different symbols are significantly different, $P<0.05$.

cumulus cells after treatment with carnitine and/or palmitic acid, as stimulation of this metabolic pathway or provision of extracellular substrates may increase FAO pathway activity. However, in the presence of a FAO inhibitor (etomoxir), transcript abundance of FAO genes would decrease and abundance of glucose transport genes would increase in response to the metabolic needs of the oocyte and cumulus cells. Our results demonstrate that there tended to be an increase in abundance of Txnrd1 $(P=0.08)$, Cpt2 $(P=0.1)$, and Glrx2 $(P=0.09)$ transcripts in oocytes treated with CARN, $100 \mu \mathrm{M}$ PALM, or CARN + $100 \mu \mathrm{M}$ PALM, respectively, compared with control oocytes (Fig. 2). However, there were no significant differences in the expression of oocyte gene when the concentration of palmitic acid was lowered to $1 \mu \mathrm{M}$, in the presence or absence of carnitine $(1 \mu \mathrm{M}$ PALM and CARN + $1 \mu \mathrm{M}$ PALM), compared with control oocytes ( $P>0.05$; Fig. 2). Abundance of $C p t 2$ tended to be increased in cumulus cells after COC treatment with $1 \mu \mathrm{M}$ PALM $(P=0.07)$ or CARN $+1 \mu \mathrm{M}$ PALM $(P=0.07)$ compared with cumulus cells from untreated $C O C$ (Fig. 3). There was a significant increase in abundance of Acsl3 in cumulus cells after COC treatment with CARN $+1 \mu \mathrm{M}$ PALM compared with control cumulus cells $(P<0.05)$. Interestingly, there tended to be a decrease $(P=0.08)$ in $A c s / 3$ in cumulus cells after treatment with CARN + $100 \mu \mathrm{M}$ PALM; however, Acs/3 was not different when $100 \mu \mathrm{M}$ PALM was added without carnitine. There was a significant increase in transcript abundance of Slc2a1 in oocytes and Cpt2 and Slc2a1 in cumulus cells in response to FAO inhibition (CARN + ETO) compared with untreated oocytes and cumulus cells $(P<0.05$; Figs 2 and 3$)$.

\section{Metabolic assays}

We hypothesized that glucose consumption in the COC and intracellular lipid content of the oocyte would be increased while ATP concentration in the oocyte would be decreased after treatment with etomoxir compared with control oocytes, as the oocyte might increase glucose consumption to compensate for decreased energy production via FAO in the COC. Furthermore, supplementation of exogenous FAO stimulators and fatty acids would decrease glucose consumption and lipid content, as the oocyte increased its level of FAO. Our results demonstrated that there was a significant decrease in glucose consumption per COC after treatment with CARN compared with the control $(P<0.05 ;$ Fig. 4A). There was no difference in glucose consumption per COC after maturation in 1 or $100 \mu \mathrm{M}$ PALM alone or in combination with carnitine compared with controls ( $P>0.05$; Fig. $4 \mathrm{~A}$ and $\mathrm{B})$. There was also no significant difference in ATP concentration per oocyte after any experimental treatment compared with control oocytes, except that treatment with $1 \mu \mathrm{M}$ PALM $(0.19 \pm$ $0.04 \mathrm{pmol}$ ATP/oocyte) significantly increased ATP concentration per oocyte compared with control oocytes $(0.06 \pm 0.01$ pmol ATP/oocyte; $P<0.05)$.

Oocyte maturation in CARN or CARN $+1 \mu \mathrm{M}$ PALM significantly reduced intracellular lipid content compared with control oocytes $(P<0.05$; Fig. 5A). However, there was no significant difference in lipid content in oocytes matured in $1 \mu \mathrm{M}$ PALM $(P>0.05)$. When concentrations of palmitic acid were increased
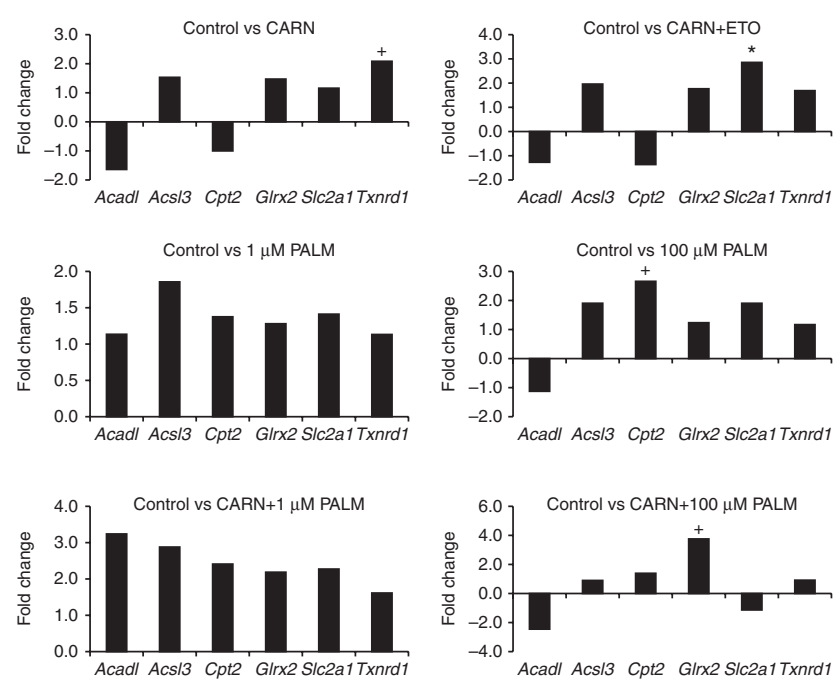

Figure 2 Transcript abundance in oocytes after maturation with $1 \mathrm{mM}$ carnitine (CARN), $1 \mu \mathrm{M}$ palmitic acid ( $1 \mu \mathrm{M}$ PALM), $100 \mu \mathrm{M}$ PALM, carnitine plus $1 \mu \mathrm{M}$ palmitic acid (CARN + $1 \mu \mathrm{M}$ PALM), CARN + $100 \mu \mathrm{M}$ PALM, or carnitine plus $100 \mu \mathrm{M}$ etomoxir (CARN + ETO). Genes related to FAO (acyl-coenzyme A dehydrogenase long chain (Acadl), acyl-CoA synthetase long-chain family member 3 (Acs/3), and carnitine palmitoyltransferase 2 (Cpt2)), glucose transport (glucose transporter 1 (S/C2a1)), and oxidative stress (glutaredoxin 2 (Glrx2) and thioredoxin reductase 1 (Txnrd1)) were analyzed. ${ }^{*} P<0.05$ and $+P<0.1$. 

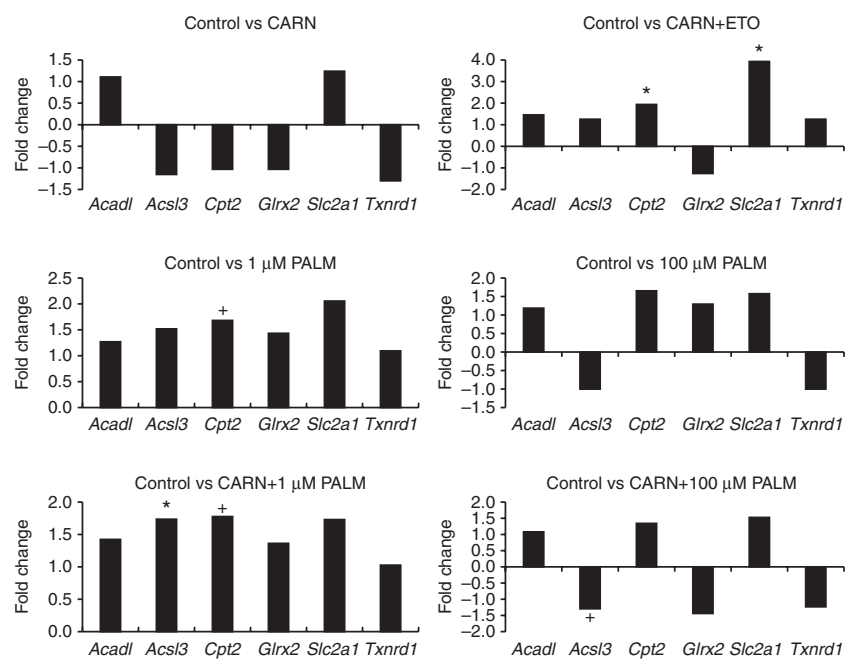

Figure 3 Transcript abundance in cumulus cells after oocyte maturation with $1 \mathrm{mM}$ carnitine (CARN), $1 \mu \mathrm{M}$ palmitic acid ( $1 \mu \mathrm{M}$ PALM), $100 \mu \mathrm{M}$ PALM, carnitine plus $1 \mu \mathrm{M}$ palmitic acid (CARN $+1 \mu \mathrm{M}$ PALM), CARN + $100 \mu \mathrm{M}$ PALM, or carnitine plus $100 \mu \mathrm{M}$ etomoxir (CARN + ETO). Genes related to FAO (acyl-coenzyme A dehydrogenase long chain (Acadl), acyl-CoA synthetase long-chain family member 3 (Acs/3), and carnitine palmitoyltransferase 2 (Cpt2)), glucose transport (glucose transporter $1(S / c 2 a 1)$ ), and oxidative stress (glutaredoxin 2 (Glrx2) and thioredoxin reductase 1 (Txnrd1)) were analyzed. ${ }^{*} P<0.05$ and ${ }^{+} P<0.1$.

(100 $\mu \mathrm{M}$ PALM), there was a significant increase in intracellular lipid content compared with control oocytes (Fig. 5B). Carnitine in conjunction with high concentrations of palmitic acid (CARN + $100 \mu \mathrm{M}$ PALM) was able to rescue intracellular lipid content to levels comparable with the control oocytes ( $P>0.05$; Fig. 5B). Oocytes derived from $\mathrm{COC}$ treated with etomoxir during maturation had significantly less lipid content than all other treatments $(P<0.05$; Fig. 5A).

\section{Discussion}

The findings of this study have further clarified the role of lipids during mouse oocyte maturation. Although FAO was not directly measured, the use of agents known to inhibit FAO during maturation of the mouse COC, even at concentrations that do not affect nuclear maturation or embryo cleavage, negatively impacted oocyte quality resulting in impaired blastocyst development and reduced embryo quality. Similarly, use of a reagent that stimulates FAO, such as carnitine, during oocyte maturation increased blastocyst development but not embryo quality. In addition, elevated levels of exogenous palmitic acid during in vitro oocyte maturation negatively impacted subsequent embryo cleavage and blastocyst development. The addition of agents that stimulate or inhibit FAO during IVM of mouse COC resulted in changes in expression of genes related to redox balance, fatty acid metabolism, and glucose transport in both cumulus cells and the oocyte itself, and directly affected intracellular lipid content of the oocyte. Interestingly, glucose consumption and fatty acid metabolism appear to be related in the mouse COC. This has also been proposed in bovine embryos following treatment of oocytes with elevated fatty acids (Van Hoeck et al. 2011). Thus, for optimal oocyte quality, it appears essential that FAO and intracellular lipid content are controlled within a tolerated range during in vitro oocyte maturation in the mouse.

In these experiments, supplementation of exogenous carnitine to stimulate $\mathrm{FAO}$ in the $\mathrm{COC}$ during maturation increased embryonic development post fertilization, but did not alter embryo quality, as reflected by total cell number and cell allocation in the resulting blastocysts. Stimulation of FAO with carnitine reduced intracellular lipid content in the oocyte, demonstrating that carnitine increased utilization of intracellular fatty acid stores. Interestingly, provision of extracellular palmitic acid at a low concentration $(1 \mu \mathrm{M})$ could not maintain intracellular lipid content in the presence of carnitine. Conflicting data exists in the literature regarding the benefit of carnitine, and thus an increase in FAO, during in vitro oocyte maturation in a number of species. It is important to note that these studies were performed in different species with varying amounts of intracellular lipids, which could have a dramatic effect on how carnitine influences oocyte competence. Supplementation of
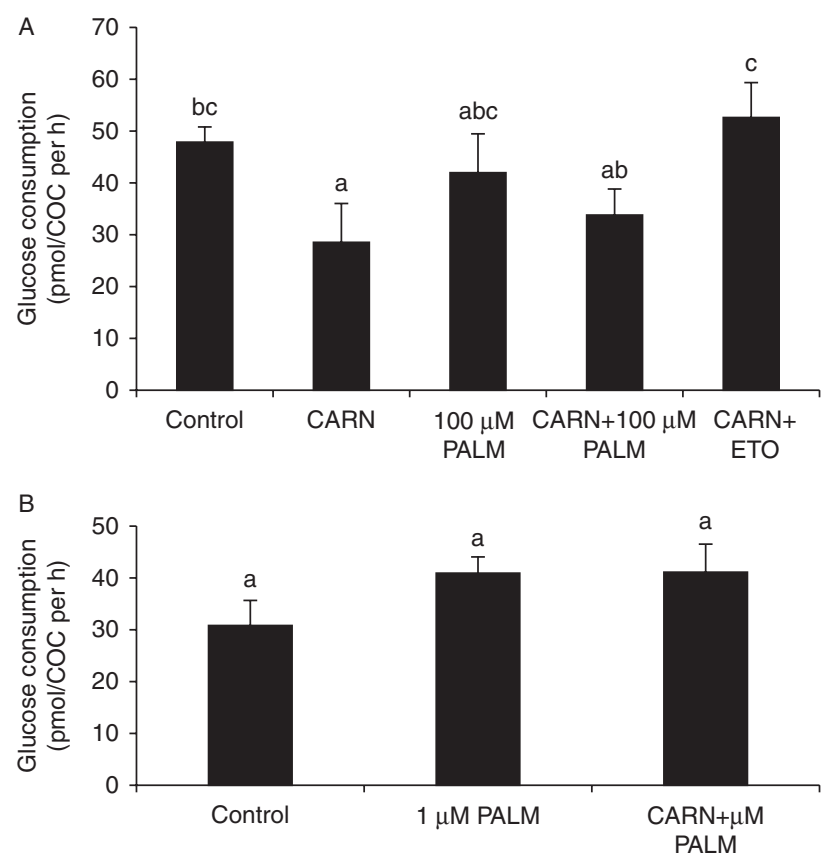

Figure 4 (A) Glucose consumption per COC after maturation with $1 \mathrm{mM}$ carnitine (CARN), $100 \mu \mathrm{M}$ palmitic acid (100 $\mu \mathrm{M}$ PALM), carnitine plus $100 \mu \mathrm{M}$ palmitic acid (CARN +100 $\mu \mathrm{M}$ PALM), or carnitine plus $100 \mu \mathrm{M}$ etomoxir (CARN + ETO) and (B) glucose consumption per COC after maturation with $1 \mu \mathrm{M}$ palmitic acid $(1 \mu \mathrm{M}$ PALM) or carnitine plus $1 \mu \mathrm{M}$ palmitic acid (CARN $+1 \mu \mathrm{M}$ PALM). ${ }^{a, b, c}$ Columns across treatments with different letters are significantly different, $P<0.05$. 

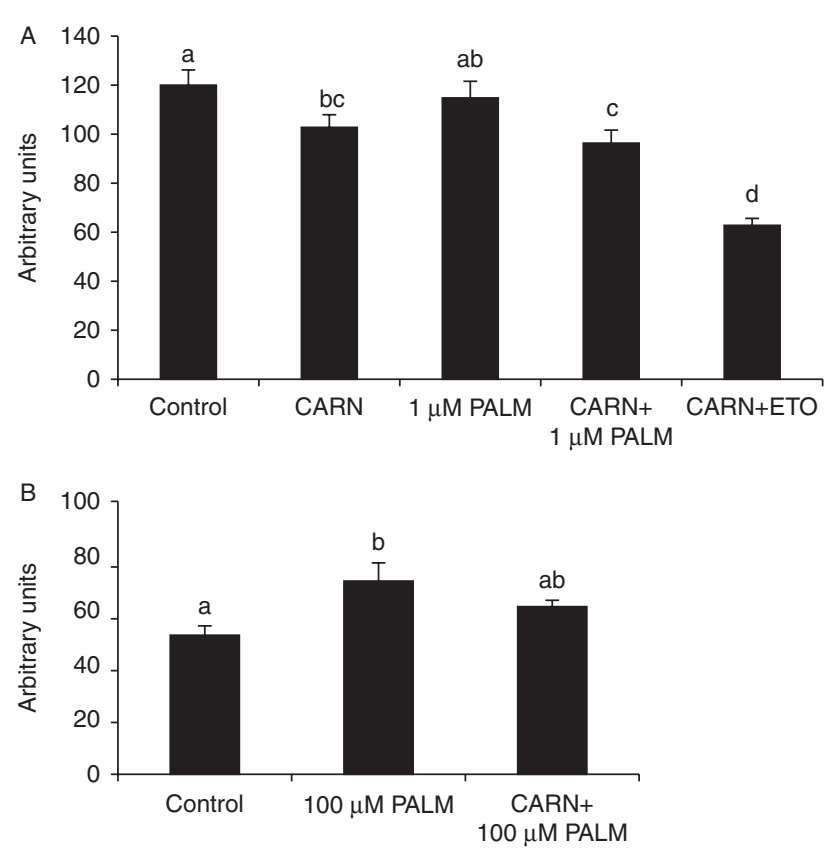

Figure 5 (A) Lipid content in oocytes after maturation with $1 \mathrm{mM}$ carnitine (CARN), $1 \mu \mathrm{M}$ palmitic acid ( $1 \mu \mathrm{M}$ PALM), carnitine plus $1 \mu \mathrm{M}$ palmitic acid (CARN $+1 \mu \mathrm{M}$ PALM), or carnitine plus $100 \mu \mathrm{M}$ etomoxir (CARN +ETO) and (B) lipid content in oocytes after maturation with $100 \mu \mathrm{M}$ PALM or CARN + $100 \mu \mathrm{M}$ PALM.

$\mathrm{a}, \mathrm{b}, \mathrm{c}, \mathrm{d}$ Columns across treatments with different letters are significantly different, $P<0.05$.

maturation medium with $0.6 \mathrm{mg} / \mathrm{ml}(\sim 3 \mathrm{mM})$ carnitine had no effect on nuclear maturation in bovine oocytes (Chankitisakul et al. 2013) or on blastocyst development in hybrid mice (Moawad et al. 2013). Addition of carnitine at concentrations ranging from 0.3 to $5 \mathrm{mg} / \mathrm{ml}$ (1.5-25 mM) during maturation of porcine oocytes had no effect on subsequent blastocyst development post fertilization (Somfai et al. 2011). Supplementation of carnitine during maturation of bovine oocytes tended to increase ATP content (Chankitisakul et al. 2013), in contrast to our results in mice; however, a higher concentration of carnitine $(\sim 3 \mathrm{mM})$ was used in the bovine study. In humans, carnitine is present in follicular fluid but concentration is not correlated with the success of assisted reproduction (Montjean et al. 2012). In another study with hybrid mice, the addition of carnitine to stimulate FAO during oocyte maturation did not affect blastocyst development, although embryos were more advanced with increased ICM with cells reflecting increased embryo quality (Dunning et al. 2010), which we did not observe. Although similar concentrations of carnitine (1 mM) were used by Dunning et al. (2010) and in the current experiment, differences observed regarding the effect of carnitine on embryo development and quality could be due in part to differences in maturation media. For example, the increased concentration of glucose $(8.6 \mathrm{mM}$ glucose compared with $0.5 \mathrm{mM}$ glucose in our maturation media) used by Dunning et al. (2010) could have provided an alternative energy substrate to the oocyte. If carnitine were to stimulate FAO in mouse oocytes to a point that depleted intracellular fatty acid stores, the COC may be able to switch to other energy substrates to sustain oocyte quality. That glucose might act in this manner is suggested by the increase we observed in Slc2a1 transcripts, a glucose transporter, in both oocytes and cumulus cells when FAO was inhibited using etomoxir. That glucose and fatty acid metabolism may be conversely related is also supported by the decrease in glucose consumption by the COC in the presence of carnitine that we observed.

Data obtained from the current experiment and previous reports indicate that oocyte intracellular lipid content and developmental competence are correlated, and that there is an optimal range of intracellular lipids that is compatible with high oocyte quality. Good quality bovine oocytes have high levels of intracellular lipids which appears optimal for this species, as oocytes with low lipid content have reduced developmental potential (Jeong et al. 2009). Bovine oocytes that were denuded before maturation had decreased developmental competence and had significantly less lipid content than cumulus enclosed oocytes (Auclair et al. 2013), suggesting that cumulus cells help to regulate the accumulation and/or metabolism of intracellular lipids during oocyte maturation. On the other hand, lipotoxicity in mouse oocytes, resulting from elevated intracellular lipid storage due to a high fat diet, is associated with decreased mitochondrial membrane potential and fertilization, suggesting decreased oocyte competence (Wu et al. 2010). In our experiment, inhibition of FAO with etomoxir significantly decreased lipid content within the oocyte, which was associated with decreased embryonic development post fertilization. Decreased oocyte quality was also associated with elevated intracellular lipids when excess palmitic acid was present in the media. However, a moderate decrease in intracellular lipids induced by carnitine improved subsequent embryo development. Developmental competence may be directly related to levels of intracellular lipid, but more likely lipid content indirectly reflects a balance in the activity of multiple metabolic pathways necessary to successfully support future embryo development.

Supplementation of fatty acids has been demonstrated to affect oocyte maturation and embryonic development in other species. In bovine oocytes, supplementation of $\alpha$-linolenic acid during oocyte maturation increased the percentage of oocytes resuming meiosis and progressing to metaphase II (Marei et al. 2012). However, supplementation of a different fatty acid, linoleic acid, decreased nuclear maturation in bovine oocytes (Marei et al. 2012). High concentrations of stearic and palmitic acid present during oocyte maturation in cattle 
decreases subsequent blastocyst development and cell number, and increases the number of apoptotic cells within the blastocyst (Van Hoeck et al. 2011). Supplementation of palmitic acid alone during bovine oocyte maturation, at concentrations used in the current experiment $(100 \mu \mathrm{M})$, significantly decreased cleavage and development to the eight-cell stage, and higher concentrations negatively affected blastocyst development (Aardema et al. 2011). Elevated levels of free fatty acids in follicular fluid are also associated with poor COC morphology in infertility patients undergoing assisted reproduction (Jungheim et al. 2011). In the current experiment, we observed a similar negative effect of elevated fatty acids during oocyte maturation. Maturation medium supplemented with a high concentration of palmitic acid $(100 \mu \mathrm{M})$ inhibited nuclear maturation, with or without carnitine. Elevated levels of palmitic acid alone were also inhibitory to embryo cleavage and preimplantation embryo development. Even low levels of palmitic acid $(1 \mu \mathrm{M})$ decreased development to the blastocyst stage (of cleaved embryos), and $1 \mu \mathrm{M}$ palmitic acid, with or without carnitine, decreased ICM cell numbers, potentially reflecting reduced embryo quality.

We also demonstrated a significant increase in oocyte intracellular lipids after treatment with elevated palmitic acid during maturation. This suggests that lipids can be taken up by mouse COC from their environment, and that in an elevated fatty acid environment the accumulation of lipids in the oocyte cytoplasm reaches levels that have negative consequences for oocyte quality. This decrease in embryo cleavage and development after exposure to and uptake of exogenous palmitic acid from the environment is similar to that observed in bovine oocytes after exposure to 100 and $250 \mu \mathrm{M}$ palmitic acid during oocyte maturation (Aardema et al. 2011). However, bovine oocytes appear to metabolize these fatty acids, as intracellular oocyte lipid droplet size was decreased after exposure to higher concentrations $(250 \mu \mathrm{M})$ of palmitic acid, although the number of lipid droplets per oocyte was unchanged until very elevated $(500 \mu \mathrm{M})$ concentrations were used, when lipid droplets per oocyte also decreased (Aardema et al. 2011). This is contrary to what was observed in the current experiment, where exogenous fatty acids resulted in increased intracellular oocyte lipid content, although the concentrations of palmitic acid used in the current study were lower than those used to elicit a response by Aardema et al. (2011). In addition, there may be species-specific differences in oocyte fatty acid metabolism between the cow and mouse, resulting in differences in storage vs utilization. Similar to what we observed in mouse oocytes, Ferguson \& Leese (1999) demonstrated that bovine embryos cultured in vitro take up and store triglycerides from the culture medium if serum is included. It is likely that species differences in the accumulation and utilization of intracellular lipid stores exist, given the differences in amount of intracellular lipids observed in the mouse and bovine oocyte (Genicot et al. 2005). The mouse oocyte appears to have a finite ability to metabolize these fatty acids, although supplementation of maturation media with carnitine can increase this capacity, reducing intracellular lipids and increasing subsequent embryo development to levels equal to control oocytes. From our results we are unable to determine whether FAO was increased in the presence of carnitine and elevated palmitic acid and whether the intracellular lipid stores were maintained by the incorporation of the palmitic acid supplied in the medium, or whether higher concentrations of palmitic acid inhibited FAO resulting in no change in intracellular lipid levels. However, the increase in Cpt2 expression in oocytes in the presence of elevated palmitic acid suggests that FAO may be increased. Low levels of palmitic acid did increase oocyte ATP content, again suggesting that oocytes can take up fatty acids from the environment and metabolize them via FAO. However, development was negatively affected in this treatment and embryo quality may have been reduced. Based on our work and that of others, elevated levels of at least some fatty acids are detrimental to oocyte quality, resulting in compromised embryo development. Although palmitic, stearic, and linoleic acids are present in follicular fluid of cattle (Renaville et al. 2010), and potentially also in follicular fluid of mouse, the benefit of fatty acids during oocyte maturation in vitro may be dependent on the specific fatty acid(s) and the concentration at which it is supplemented, as well as species.

Concurrent with the increase in FAO via carnitine supplementation, we observed a decrease in glucose consumption, suggesting an inverse relationship between these two metabolic pathways in the COC. The increased ability of the COC to utilize fatty acids as an energy substrate may decrease the need for the COC to metabolize glucose, or allow glucose to be stored or directed to other essential pathways. The 'glucose-fatty acid cycle' is an important concept which describes the inter-regulation of glucose and fatty acid metabolism to maintain homeostasis (Holness \& Sugden 2003). In a previous study, we showed that abundance of $P f k m$ (Pfk1), which is involved in the glycolytic pathway, was increased in bovine oocytes after inhibition of FAO, corresponding to an increase in glucose uptake by the COC (Paczkowski et al. 2013). Inhibition of fatty acid metabolism in mouse and pig embryos also results in changes in glucose metabolism (Hewitson et al. 1996, Sturmey et al. 2009). Similarly, obese mice had decreased blastocyst expression of Slc2a1 compared with non-obese mice, suggesting a downregulation of glucose uptake when fatty acid levels are elevated (Bermejo-Alvarez et al. 2012). Elevated serum glucose levels in pregnant women correspond to reduced levels of CPT1 activity in placental extracts, thereby decreasing FAO (Visiedo et al. 2013). Furthermore, overexpression 
of glucose transporter S/c2a1 in mouse cardiac tissue increases glucose uptake and oxidation while decreasing FAO, despite a high supply of fatty acids (Yan et al. 2009). A relationship between FAO and glucose consumption and oxidation has also been reported in rat hepatocytes (Berry et al. 1993), rat myocytes (Abdel-aleem et al. 1994), rat skeletal muscle (Kaushik et al. 2001), and rat (Saddik et al. 1993, Lavrentyev et al. 2004) and mouse cardiac tissues (Campbell et al. 2002).

Genes associated with oxidative stress tended to increase in abundance in oocytes after maturation with a stimulator of FAO (carnitine), or when carnitine and palmitic acid were supplemented together. The data indicate that oxidative stress is increased in oocytes when FAO increases, resulting in a concurrent increase in abundance of genes to maintain redox balance. These findings are reminiscent of our previous study whereby we demonstrated that inhibition of FAO with etomoxirdecreased expression of oxidative stress genes (Paczkowski et al. 2013). However, sustained inhibition of FAO may also increase oxidative stress, as excessive accumulation of fatty acids within the cytoplasm can also result in formation of reactive oxygen species (Furukawa et al. 2004).

In oocytes, stimulation or inhibition of FAO caused few changes in the expression of genes related to fatty acid metabolism (Acadl, Acs/3, and Cpt2). Previous reports indicate that stimulation of FAO with carnitine can alter oocyte and embryo gene expression. Carnitine supplementation during maturation increases the expression of both anti- and proapoptotic genes, as well as transcription factors in bovine oocytes (You et al. 2012). Bovine blastocysts, after culture with carnitine, had elevated expression of genes related to ATP synthesis and oxidative phosphorylation and decreased expression of Bax, a proapoptotic gene (Takahashi et al. 2013). High concentrations of palmitic acid, resulting in increased oocyte lipid content, and decreased development post fertilization tended to increase the expression of Cpt2, suggesting that oocytes may have increased the movement of fatty acids into the mitochondria. Whether this resulted in increased mitochondrial FAO is unknown. When carnitine is added to excess palmitic acid conditions, returning oocyte lipid content and subsequent embryo development to levels equal to control, transcription of the genes involved in fatty acid metabolism were also no longer different than in control oocytes, although Glrx2 was elevated, suggesting a possible cellular response to increased reactive oxygen species production with elevated FAO. When bovine oocytes are exposed to elevated concentrations of stearic, palmitic, and oleic acids $(425 \mu \mathrm{M}$ total), the resulting blastocysts have increased the expression of genes related to de novo methylation, cellular and oxidative stress, and glucose metabolism, leading to disrupted oocyte and embryo metabolism (Van Hoeck et al. 2011, 2013). Abundance of ER stress markers are also elevated in COC from mice fed a high-fat diet and in granulosa cells from obese women (Wu et al. 2010). Our gene expression results would also indicate that increased fatty acids in maturation medium leads to aberrant gene expression and metabolism.

Conversely, more changes were observed in expression of these genes in cumulus cells. Surprisingly, Cpt2 expression was elevated in cumulus cells when FAO was inhibited. This is in agreement with our previously reported findings in mouse and bovine oocytes, that etomoxir treatment, at a concentration that did not affect completion of nuclear maturation, reduced oocyte lipid content (Paczkowski et al. 2013). Etomoxir treatment also decreased oocyte lipid content in this study. We hypothesize that in the COC, FAO may undergo an initial increase in activity as a response to etomoxir, increasing transcription of essential FAO genes, and briefly metabolizing lipids before inhibition. This hypothesis is supported by recent reports in mouse COC where expression of genes involved in FAO were altered after FAO inhibition (Brisard et al. 2014). Abundance of genes involved in FAO is also increased in COC after treatment with rosiglitazone, an agent known to inhibit FAO (Dunning et al. 2014). Similar to the observed increase in Cpt2 transcripts in cumulus cells after maturation with low levels of palmitic acid, with or without carnitine, an increase in Cpt1 has been documented in pancreatic cell lines when palmitate, oleate, and linoleate are supplied (AssimacopoulosJeannet et al. 1997). After maturation with low palmitic acid concentrations and carnitine, Cpt2 and Acs/3 gene transcripts were elevated in cumulus cells, suggesting that FAO may have been increased in this treatment. Although we did not observe similar changes in the expression of these genes in oocytes (a nonsignificant increase of 2.5- to threefold was detected), a decrease in lipid content in oocytes in the presence of low palmitic acid was observed, suggesting increased lipid metabolism. This result indicates that expression of genes related to fatty acid metabolism in the cumulus cells reflect the status of lipids in the oocyte itself, even when significant changes in transcription of these genes in the oocyte are not detected. This is further supported by recent work in cattle, suggesting that cumulus cells have an essential role in regulating lipid metabolism of the oocyte (Auclair et al. 2013).

In conclusion, oocyte quality, as reflected by subsequent embryo development, is negatively impacted when FAO is inhibited or when oocytes are exposed to an elevated concentration of fatty acid, demonstrating the importance of fatty acid metabolism to optimal oocyte maturation. Increasing fatty acid metabolism with carnitine partially negates the negative effects of elevated fatty acids during maturation, and carnitine alone can be beneficial to subsequent embryo development. These results indicate that lipid metabolism, as well as related 
intracellular lipid stores, is important to oocyte quality, but must be finely balanced within a specific range to support developmental competence. However, we found no benefit from the supplementation of low concentrations of palmitic acid during IVM on oocyte quality in the mouse. Of particular interest, there appears to be a carefully orchestrated balance between glucose and fatty acid metabolism in mouse COC, in which increased FAO results in reduced lipid content and lowered glucose consumption, while increasing oocyte competence.

\section{Declaration of interest}

The authors declare that there is no conflict of interest that could be perceived as prejudicing the impartiality of the research reported.

\section{Funding}

This research did not receive any specific grant from any funding agency in the public, commercial or notfor-profit sector.

\section{References}

Aardema H, Vos PL, Lolicato F, Roelen BA, Knijn HM, Vaandrager AB, Helms JB \& Gadella BM 2011 Oleic acid prevents detrimental effects of saturated fatty acids on bovine oocyte developmental competence. Biology of Reproduction 85 62-69. (doi:10.1095/biolreprod.110. 088815)

Abdel-aleem S, Li X, Anstadt MP, Perez-Tamayo RA \& Lowe JE 1994 Regulation of glucose utilization during the inhibition of fatty acid oxidation in rat myocytes. Hormone and Metabolic Research 26 88-91. (doi:10.1055/s-2007-1000779)

Assimacopoulos-Jeannet F, Thumelin S, Roche E, Esser V, McGarry JD \& Prentki M 1997 Fatty acids rapidly induce the carnitine palmitoyltransferase I gene in the pancreatic $\beta$-cell line INS-1. Journal of Biological Chemistry 272 1659-1664. (doi:10.1074/jbc.272.3.1659)

Auclair S, Uzbekov R, Elis S, Sanchez L, Kireev I, Lardic L, Dalbies-Tran R \& Uzbekova S 2013 Absence of cumulus cells during in vitro maturation affects lipid metabolism in bovine oocytes. American Journal of Physiology. Endocrinology and Metabolism 304 E599-E613. (doi:10. 1152/ajpendo.00469.2012)

Berg JM, Tymoczko JL \& Stryer L 2002 Fatty Acid Metabolism. In: Biochemistry, Fifth Edition, pp 605-610. New York: W.H. Freeman.

Bermejo-Alvarez P, Rosenfeld CS \& Roberts RM 2012 Effect of maternal obesity on estrous cyclicity, embryo development and blastocyst gene expression in a mouse model. Human Reproduction 27 3513-3522. (doi:10.1093/humrep/des327)

Berry MN, Phillips JW, Henly DC \& Clark DG 1993 Effects of fatty acid oxidation on glucose utilization by isolated hepatocytes. FEBS Letters 319 26-30. (doi:10.1016/0014-5793(93)80030-X)

Biggers JD, Whittingham DG \& Donahue RP 1967 The pattern of energy metabolism in the mouse oocyte and zygote. PNAS 58 560-567. (doi:10. 1073/pnas.58.2.560)

Brisard D, Chesnel F, Elis S, Desmarchais A, Sanchez-Lazo L, Chasles M, Maillard V \& Uzbekova S 2014 Tribbles expression in cumulus cells is related to oocyte maturation and fatty acid metabolism. Journal of Ovarian Research 44 1-13. (doi:10.1186/1757-2215-7-44)

Campbell FM, Kozak R, Wagner A, Altarejos JY, Dyck JR, Belke DD, Severson DL, Kelly DP \& Lopaschuk GD 2002 A role for peroxisome proliferator-activated receptor alpha (PPAR $\alpha$ ) in the control of cardiac malonyl-CoA levels: reduced fatty acid oxidation rates and increased glucose oxidation rates in the hearts of mice lacking PPAR $\alpha$ are associated with higher concentrations of malonyl-CoA and reduced expression of malonyl-CoA decarboxylase. Journal of Biological Chemistry 277 4098-4103. (doi:10.1074/jbc.M106054200)

Chankitisakul V, Somfai T, Inaba Y, Techakumphu M \& Nagai T 2013 Supplementation of maturation medium with L-carnitine improves cryo-tolerance of bovine in vitro matured oocytes. Theriogenology 79 590-598. (doi:10.1016/j.theriogenology.2012.11.011)

National Research Council 2011 Guide for the Care and Use of Laboratory Animals: Eighth Edition. Washington, DC: National Academies Press.

Downs SM \& Mastropolo AM 1994 The participation of energy substrates in the control of meiotic maturation in murine oocytes. Developmental Biology 162 154-168. (doi:10.1006/dbio.1994.1075)

Downs SM, Mosey JL \& Klinger J 2009 Fatty acid oxidation and meiotic resumption in mouse oocytes. Molecular Reproduction and Development 76 844-853. (doi:10.1002/mrd.21047)

Dunning KR, Cashman K, Russell DL, Thompson JG, Norman RJ \& Robker RL $2010 \beta$-Oxidation is essential for mouse oocyte developmental competence and early embryo development. Biology of Reproduction 83 909-918. (doi:10.1095/biolreprod.110.084145)

Dunning KR, Anastasi MR, Zhang VJ, Russell DL \& Robker RL 2014 Regulation of fatty acid oxidation in mouse cumulus-oocyte complexes during maturation and modulation by PPAR agonists. PLOS ONE 9 e87327 (1-11). (doi:10.1371/journal.pone.0087327)

Ferguson EM \& Leese HJ 1999 Triglyceride content of bovine oocytes and early embryos. Journal of Reproduction and Fertility 116 373-378. (doi:10.1530/jrf.0.1160373)

Ferguson EM \& Leese HJ 2006 A potential role for triglyceride as an energy source during bovine oocyte maturation and early embryo development. Molecular Reproduction and Development 73 1195-1201. (doi:10. 1002/mrd.20494)

Furukawa S, Fujita T, Shimabukuro $M$, Iwaki M, Yamada $Y$, Nakajima $Y$, Nakayama O, Makishima M, Matsuda M \& Shimomura I 2004 Increased oxidative stress in obesity and its impact on metabolic syndrome. Journal of Clinical Investigation 114 1752-1761. (doi:10.1172/JCI21625)

Genicot G, Leroy JL, Soom AV \& Donnay I 2005 The use of a fluorescent dye, Nile red, to evaluate the lipid content of single mammalian oocytes. Theriogenology 63 1181-1194. (doi:10.1016/j.theriogenology. 2004.06.006)

Herrick JR, Brad AM \& Krisher RL 2006a Chemical manipulation of glucose metabolism in porcine oocytes: effects on nuclear and cytoplasmic maturation in vitro. Reproduction 131 289-298. (doi:10.1530/rep.1.00835)

Herrick JR, Lane M, Gardner DK, Behboodi E, Memili E, Blash S, Echelard Y \& Krisher RL 2006b Metabolism, protein content, and in vitro embryonic development of goat cumulus-oocyte complexes matured with physiological concentrations of glucose and L-lactate. Molecular Reproduction and Development 73 256-266. (doi:10.1002/mrd.20407)

Herrick JR, Strauss KJ, Schneiderman A, Rawlins M, Stevens J, Schoolcraft WB \& Krisher RL 2014 The beneficial effects of reduced magnesium during the oocyte-to-embryo transition are conserved in mice, domestic cats and humans. Reproduction, Fertility, and Development. In press. (doi:10.1071/RD13268)

Hewitson LC, Martin KL \& Leese HJ 1996 Effects of metabolic inhibitors on mouse preimplantation embryo development and the energy metabolism of isolated inner cell masses. Molecular Reproduction and Development 43 323-330. (doi:10.1002/(SICl)1098-2795(199603)43:3<323::AIDMRD6 > 3.0.CO;2-S)

Holness MJ \& Sugden MC 2003 Regulation of pyruvate dehydrogenase complex activity by reversible phosphorylation. Biochemical Society Transactions 31 1143-1151. (doi:10.1042/BST0311143)

Jeong WJ, Cho SJ, Lee HS, Deb GK, Lee YS, Kwon TH \& Kong IK 2009 Effect of cytoplasmic lipid content on in vitro developmental efficiency of bovine IVP embryos. Theriogenology 72 584-589. (doi:10.1016/j. theriogenology.2009.04.015)

Jungheim ES, Macones GA, Odem RR, Patterson BW, Lanzendorf SE, Ratts VS \& Moley KH 2011 Associations between free fatty acids, cumulus oocyte complex morphology and ovarian function during in vitro fertilization. Fertility and Sterility 95 1970-1974. (doi:10.1016/ j.fertnstert.2011.01.154)

Kaushik VK, Young ME, Dean DJ, Kurowski TG, Saha AK \& Ruderman NB 2001 Regulation of fatty acid oxidation and glucose metabolism in rat soleus muscle: effects of AICAR. American Journal of Physiology. Endocrinology and Metabolism 281 E335-E340. 
Lavrentyev EN, He D \& Cook GA 2004 Expression of genes participating in regulation of fatty acid and glucose utilization and energy metabolism in developing rat hearts. American Journal of Physiology. Heart and Circulatory Physiology 287 H2035-H2042. (doi:10.1152/ajpheart. 00372.2004)

Leroy JL, Vanholder T, Mateusen B, Christophe A, Opsomer G, de Kruif A, Genicot G \& Van Soom A 2005 Non-esterified fatty acids in follicular fluid of dairy cows and their effect on developmental capacity of bovine oocytes in vitro. Reproduction 130 485-495. (doi:10.1530/rep.1.00735)

Littell RC, Milliken GA, Stroup WW \& Wolfinger RD 1996 SAS System for Mixed Models, First Edition, pp 423-460. Cary, North Carolina: SAS Institute, Incorporated.

Marei WF, Wathes DC \& Fouladi-Nashta AA 2012 Differential effects of linoleic and $\alpha$-linolenic fatty acids on spatial and temporal mitochondrial distribution and activity in bovine oocytes. Reproduction, Fertility, and Development 24 679-690. (doi:10.1071/RD11204)

McGarry JD \& Brown NF 1997 The mitochondrial carnitine palmitoyltransferase systeml. From concept to molecular analysis. European Journal of Biochemistry 244 1-14. (doi:10.1111/j.1432-1033.1997.00001.x)

Moawad AR, Tan SL, Xu B, Chen HY \& Taketo T 2013 L-carnitine supplementation during vitrification of mouse oocytes at the germinal vesicle stage improves preimplantation development following maturation and fertilization in vitro. Biology of Reproduction 104 1-8. (doi:10.1095/biolreprod.112.107433)

Montjean D, Entezami F, Lichtblau I, Belloc S, Gurgan T \& Menezo Y 2012 Carnitine content in the follicular fluid and expression of the enzymes involved in $\beta$ oxidation in oocytes and cumulus cells. Journal of Assisted Reproduction and Genetics 29 1221-1225. (doi:10.1007/s10815-0129855-2)

Nagy A, Gertsenstein M, Vintersten K, Behringer R 2003 Assisted Reproduction: Ovary transplantation, In Vitro Fertilization, Artifdicial Inasemination, and Intracytoplasmic Sperm Injection. In Manipulating the Mouse Embryo: a Laboratory Manual, Third Edition, pp 565-597. Cold Spring Harbor, NY: Cold Spring Harbor Laboratory Press.

Paczkowski M, Yuan Y, Fleming-Waddell J, Bidwell CA, Spurlock D \& Krisher RL 2011 Alterations in the transcriptome of porcine oocytes derived from prepubertal and cyclic females is associated with developmental potential. Journal of Animal Science 89 3561-3571. (doi:10.2527/jas.2011-4193)

Paczkowski M, Silva E, Schoolcraft WB \& Krisher RL 2013 Comparative importance of fatty acid $\beta$-oxidation to nuclear maturation, gene expression, and glucose metabolism in mouse, bovine, and porcine cumulus oocyte complexes. Biology of Reproduction 111 1-11. (doi:10. 1095/biolreprod.113.108548)

Pfaffl MW, Horgan GW \& Dempfle L 2002 Relative expression software tool (REST) for group-wise comparison and statistical analysis of relative expression results in real-time PCR. Nucleic Acids Research 30 e36 (1-10). (doi:10.1093/nar/30.9.e36)

Renaville B, Bacciu N, Comin A, Motta M, Poli I, Vanini G \& Prandi A 2010 Plasma and follicular fluid fatty acid profiles in dairy cows. Reproduction in Domestic Animals 45 118-121. (doi:10.1111/j.1439-0531.2008. 01264.x)

Rozen S \& Skaletsky H 2000 Primer3 on the WWW for general users and for biologist programmers. Methods in Molecular Biology 132 365-386.

Saddik M, Gamble J, Witters LA \& Lopaschuk GD 1993 Acetyl-CoA carboxylase regulation of fatty acid oxidation in the heart. Journal of Biological Chemistry 268 25836-25845.

Somfai T, Kaneda M, Akagi S, Watanabe S, Haraguchi S, Mizutani E, DangNguyen TQ, Geshi M, Kikuchi K \& Nagai T 2011 Enhancement of lipid metabolism with L-carnitine during in vitro maturation improves nuclear maturation and cleavage ability of follicular porcine oocytes. Reproduction, Fertility, and Development 23 912-920. (doi:10.1071/RD10339)
Spindler RE, Pukazhenthi BS \& Wildt DE 2000 Oocyte metabolism predicts the development of cat embryos to blastocyst in vitro. Molecular Reproduction and Development 56 163-171. (doi:10.1002/(SICl)10982795(200006)56:2 <163::AID-MRD7> 3.0.CO;2-3)

Sturmey RG, O'Toole PJ \& Leese HJ 2006 Fluorescence resonance energy transfer analysis of mitochondrial:lipid association in the porcine oocyte. Reproduction 132 829-837. (doi:10.1530/REP-06-0073)

Sturmey RG, Reis A, Leese HJ \& McEvoy TG 2009 Role of fatty acids in energy provision during oocyte maturation and early embryo development. Reproduction in Domestic Animals 44 (Suppl 2) 50-58. (doi:10. 1111/j.1439-0531.2009.01402.x)

Takahashi T, Inaba Y, Somfai T, Kaneda M, Geshi M, Nagai T \& Manabe N 2013 Supplementation of culture medium with L-carnitine improves development and cryotolerance of bovine embryos produced in vitro. Reproduction, Fertility, and Development 25 589-599. (doi:10.1071/ RD11262)

Thouas GA, Korfiatis NA, French AJ, Jones GM \& Trounson AO 2001 Simplified technique for differential staining of inner cell mass and trophectoderm cells of mouse and bovine blastocysts. Reproductive Biomedicine Online 3 25-29. (doi:10.1016/S1472-6483(10)61960-8)

Valsangkar D \& Downs SM 2013 A requirement for fatty acid oxidation in the hormone-induced meiotic maturation of mouse oocytes. Biology of Reproduction 43 1-9. (doi:10.1095/biolreprod.113.109058)

Van Hoeck V, Sturmey RG, Bermejo-Alvarez P, Rizos D, Gutierrez-Adan A, Leese HJ, Bols PE \& Leroy JL 2011 Elevated non-esterified fatty acid concentrations during bovine oocyte maturation compromise early embryo physiology. PLOS ONE 6 e23183 (1-8). (doi:10.1371/journal. pone.0023183)

Van Hoeck V, Leroy JL, Arias Alvarez M, Rizos D, Gutierrez-Adan A, Schnorbusch K, Bols PE, Leese HJ \& Sturmey RG 2013 Oocyte developmental failure in response to elevated nonesterified fatty acid concentrations: mechanistic insights. Reproduction 145 33-44. (doi:10. 1530/REP-12-0174)

Visiedo F, Bugatto F, Sanchez V, Cozar-Castellano I, Bartha JL \& Perdomo G 2013 High glucose levels reduce fatty acid oxidation and increase triglyceride accumulation in human placenta. American Journal of Physiology. Endocrinology and Metabolism 305 E205-E212. (doi:10. 1152/ajpendo.00032.2013)

Wu LL, Dunning KR, Yang X, Russell DL, Lane M, Norman RJ \& Robker RL 2010 High-fat diet causes lipotoxicity responses in cumulus-oocyte complexes and decreased fertilization rates. Endocrinology 151 5438-5445. (doi:10.1210/en.2010-0551)

Yan J, Young ME, Cui L, Lopaschuk GD, Liao R \& Tian R 2009 Increased glucose uptake and oxidation in mouse hearts prevent high fatty acid oxidation but cause cardiac dysfunction in diet-induced obesity. Circulation 119 2818-2828. (doi:10.1161/CIRCULATIONAHA.108. 832915)

You J, Lee J, Hyun SH \& Lee E 2012 L-carnitine treatment during oocyte maturation improves in vitro development of cloned pig embryos by influencing intracellular glutathione synthesis and embryonic gene expression. Theriogenology 78 235-243. (doi:10.1016/j.theriogenology.2012.02.027)

Received 10 January 2014

First decision 11 February 2104

Revised manuscript received 17 July 2014

Accepted 24 July 2014 